Phil. Mag.). The new measurements of such of the $L, M$, and $N$ spectra of the heavier atoms as have been repeated agree excellently with my original values (within I part in Iooo). In recording the spectrum of uranium with a target of uranium oxide, I obtained, however, a line which was clearly due to the oxygen $K$ level. This line falls about midway between the uranium $N_{\mathbf{v}}$ and $N_{\mathbf{v r}}$ levels, which are fairly widely separated. Measurements on this gave a much lower value for the oxygen $K$ level-namely, $\nu / R \quad 36.7$ instead of $42 \cdot 3$ - and this led me to redetermine the other values for the light atoms. The revised values are:

\begin{tabular}{|c|c|c|}
\hline $\begin{array}{c}\text { Element. } \\
\text { 20 Calcium }\end{array}$ & $\begin{array}{c}\nu / R K \text { Level. } \\
296 \cdot 6\end{array}$ & $\begin{array}{l}\text { Other Values. } \\
297.5 \mathrm{~F} \text {. }\end{array}$ \\
\hline I6 Sulphur & I $80 \cdot 3$ & $\mathrm{I} 8 \mathrm{I} .8 \mathrm{~F}$. \\
\hline I2 Magnesium & $93 \cdot 6$ & $95.8 \mathrm{~F}$ \\
\hline I I Sodium & $76 \cdot 6$ & \\
\hline 8 Oxygen & $3^{6 \cdot 7}$ & $\left\{\begin{array}{l}35.3 \mathrm{M} \\
38 \cdot 3 \mathrm{~K}\end{array}\right.$ \\
\hline
\end{tabular}

F. = Fricke, M. = Mohler and Foote, K. = Kurth.

It is clear from the new measurements that in the earlier experiments the Helmholtz coils must have moved. During the work on the heavier elements the magnetic fields were calibrated from time to time and found to remain perfectly constant. The light atoms were tested at the end, just before the apparatus was dismantled, and no re-calibration was made in this case. The new work shows quite clearly that only the measurements on the light atoms were affected by this accident.

H. RoBINSON.

Physical Laboratory.

The University, Edinburgh, May 27.

\section{Anomalous Dispersion and Multiplet Lines in Spectra.}

Recently, H. B. Dorgelo has carried out a series of measurements of the intensities of the components of multiple spectral lines (Dissertation, Utrecht, I924) and obtained results of great interest. He found that the doublets of the sharp series of the alkalies had a $2:$ I ratio of intensity, the triplet components of the sharp series of the alkaline earths had a $5: 3:$ I ratio, the triplets of the sharp series of a sextet system had a $4: 3: 2$ ratio, and the triplets of an octet system a $5: 4: 3$ ratio. The theoretical interpretation of this result has been discussed by Sommerfeld ("Atombau," Fourth Edition, p. 649) and by Ornstein and Burger (Zeit. für Physik, I924, 24, p. 4I). As illustrations of Dorgelo's work may be quoted the case of the triplets of manganese 6021, 6016, 6013, which show a $4: 3: 2$ intensity ratio.

Probably the best known case of the existence of simple intensity relationships of this kind are the two D-lines of sodium, for which a 2 : I ratio has long been shown. The anomalous dispersion of sodium vapour has been extensively studied, notably by Roschdestwensky, who found (Ann. der Physik, I9I2, vol. 39) that of two constants $a_{1}, a_{2}$ in the dispersion equation

$$
n=\mathrm{I}+\frac{a_{1} \lambda^{2}}{\lambda^{2}-\lambda_{1}{ }^{2}}+\frac{a_{2} \lambda^{2}}{\lambda^{2}-\lambda_{2}{ }^{2}},
$$

where $\lambda_{1}$ and $\lambda_{2}$ are the wave-lengths of the two D-lines, $a_{1}$ was just twice as large as $a_{2}$. Dorgelo's work suggests that, in the case of multiplet lines, similar numerical relationships between the constants of anomalous dispersion should be found. Unfortunately, very little in the way of quantitative data on anomalous dispersion is available except in the case of the alkali metals.

$$
\text { NO. 2903, VOL I I } 5]
$$

Perhaps the best work in this direction is that of A. S. King at Mount Wilson, who with the electric furnace studied the anomalous dispersion of iron, chromium, titanium, and manganese lines (Astrophysical Journal, I9I7, 45, p. 254). An enlarged photograph of the anomalous dispersion due to the manganese triplet 403 I, 4033, and 4035, which belongs to the sextet system, reproduced with King's paper, has been examined, and it is found that the dispersion constants $a_{1}, a_{2}$, and $a_{3}$ of the lines deduced from the photograph agree closely with the $4: 3: 2$ ratio to be expected on theoretical grounds. In the case of the chromium triplets 5208, 5206, and 5204, Dorgelo obtained experimentally an intensity ratio of I oo : $72: 45$, while King's photographs give the ratio of anomalous dispersion to be roughly as $100: 75: 50$, which is a fair agreement. A careful study of the original negatives secured at Mount Wilson may be suggested as likely to furnish further data regarding these interesting spectral relationships.

C. V. RAMAN

S. K. Datra.

\section{A New Standard Solution for Sahli's Hæmometer.}

SINCE Sahli's hæmometer has come more and more in practical use for the colorimetrical inspection of human blood, there has been no lack of experiments to obtain a standard liquid which will keep its colour in daylight better than the indicated hæmatine solution. Most experimenters have clung to Sahli's principle, that in quantitative determination of the contents of iron in blood, the standard liquid should be, so far as possible, the same as the blood solution to be examined. This research is limited to the derivatives of hæmoglobin and has not yet produced the desired result, so far as I know.

The cheapness of the instrument being admitted as a main factor, leads to the use of aniline and similar fluids as a standard. These products have not the slightest chemical relation with hæmoglobin; and they all have the fault that they do not retain colour.

A third standard is the coloured solid glass staffin fact the combination of Fleischl's and Sahli's hæmometer. Although the colour of the glass seems to last, this standard gives different results, depending upon the kind of light in which the blood determination is made.

I think it advisable to use as a standard a solution of chlorophyll (or related products-the phlobaphenes), namely, an extract of leaves, browned to the darkest tint. It has been proved to be possible to get in this way a solution imitating: absolutely. the colour of Sahli's standard, having the following advantages :

(I) Chlorophyll is from a biological and chemical point of view more similar to hæmoglobin than any other chemical product (except the hæmoglobinderivatives). This advantage is only theoretical.

(2) This solution contains a natural brown colour formed by sunlight (or a similar physical process), so that it seems logical to think it impossible that this colour, once isolated, should undergo further change.

(3) This solution is easily made and is cheap.

The simplest way of making this standard solution is as follows :- Tea leaves should be macerated for one hour in an antiformine-water mixture (for example. I-IO). The more tea leaves are taken, the darker the extract becomes. The brown extract so obtained is filtered and the antiformine solution added to it, in a clean glass tube of exactly the same size and kind as Sahli's, until the colour is that of Sahli's standard. The comparison can be made " $a$ vue" or with other 